\title{
Technical Efficiency of Dairy Production Under the Extensive Management: The Case of Eastern Dry Zone in Sri Lanka
}

\author{
E.G.C.D. Bandara ${ }^{1}$ and Parakrama Weligamage ${ }^{2}$
}

\begin{abstract}
Extensive cattle rearing system is predominant among rural dairy farmers in Sri Lanka, where the selections and opportunities for other economic activities are limited. In Sri Lanka, approximately 60-70\% of domestic dairy requirement is still dependent on imports due to the lack of domestic milk production. In this context, the study was carried out to a) analyse technical efficiency and b) its determinants of dairy production in rural areas of Batticaloa district in the Eastern Province of Sri Lanka in order to facilitate the dairy productivity. Manmunai South West Division is one of the poorest divisions in Batticaloa, which contributes 11.4 per cent to the total cattle population in the district. Data were collected from randomly selected 52 farmers using a structured survey schedule during November to December in 2016. Data on herd composition, input costs, and output per year immediately preceding the current period were collected. Cobb Douglas production function was used to model input-output relationships. Stochastic Frontier was estimated using Stata 13 and Technical Efficiency (TE) of the sample was estimated. TE scores were regressed against the selected farm and producer characteristics to find determinants of technical inefficiency. Regression coefficients of the proportion of improved/cross bred cows and the proportion of cows in lactation were positive in Stochastic Frontier model. Regression coefficients of age of the farmer, education level and herd size were negative in inefficiency model, which reflected the higher values of these variables, reduce inefficiency. The average TE of the sample was implying that there is about 50\% scope of improving the production with the same input level. The study concludes that increasing the proportion of improved/cross bred cows and proportion of cows in lactation as potential interventions in increasing efficiency of farmers from rural areas of Batticaloa who follow extensive management system.
\end{abstract}

Keywords: Peasant farming; Stochastic production frontier; Cobb-Douglas production function; Cross section data; Batticaloa district

\footnotetext{
${ }^{1}$ Project Management and Consultancy Division, Industrial Services Bureau, 141, Kandy Road, Kurunegala.

2 Department of Agricultural Economics and Business Management; University of Peradeniya.Email: parakw@pdn.ac.lk
} 


\section{Introduction}

Sustainable production and consumption is one of the 17 SDGs. Agricultural production systems are input-output systems that use resources to produce a given set of outputs. As resources are limited and agriculture generates incomes to rural masses understanding of how efficiency of input use in agriculture can lead to increasing farmer profits and use of lower resource quantities. Studies on efficiency of input use in agriculture have drawn worldwide interest.

Milk is considered globally as a nutrition rich food. Milk is produced from a domesticated sub-set of mammals. Milk and milk products are considered a part of traditional diets of Sri Lankans. Currently, cows' milk consumption supersedes milk from other animals and only 70 per cent of the quantity consumed is produced in Sri Lanka. Demand for milk and dairy products are expected to increase with increasing incomes and rise in population. Milk powder is also used as a functional ingredient of bakery products, confectionery, and local sweet-meats.

Although a well-developed international market exists for these products, there is a considerable interest to increase production within the country. Importance of the development of the dairy industry with the aim of fulfilling domestic requirement and to reduce dependence on imports of milk and milk-based products. This motive is to assure food sovereignty of the country and to refrain from suppliers adulterating and recomposing of milk with less intended or cheaper ingredients. Therefore, proper planning based on forecasting is an obligation for further development of the industry towards a better productivity in order to uplift the livelihood of the people who have been engaging with the dairy industry for years.

Dairy industry and production practices of the country were a popular topic for researchers in the past. Based on an island-wide survey, Abeygunawardena et al., (1994) categorized cattle rearing systems in Sri Lanka into four types as, (i) Dry Zone Traditional Village System (DTVS), (ii) Dry Zone Irrigated Settlement System (DISS), (iii) Intermediate Zone System (IS) and (iv) Wet Zone System (WS). Previous studies on productivity/monetary returns analysis in the dairy sector of Sri Lanka however are based on systems other than DTVS. These studies include Serasinghe, Mahipala and Gunaratne (2003); and Bandara, Premaratne and Dematawewa (2011). Studies on import patterns of milk powder Herath \& Bogahawatte (2006), more recently studies in marketing systems Gunarathne et al., (2015), and on household preference pattern of milk products was Divuldeniya \& Weligamage (2016). However, there is a clear lack of studies on productivity analysis of dry zone dairy farming systems of the country. Yet it is important to understand the productivity and their determinants as well as costs and profits of these systems due to their influence on livelihoods of a segment of smallholder farmers and to understand 
the potential contribution to increase national production. This study therefore, was carried out to; (a) analyze technical efficiency and (b) its determinants of dairy production in rural areas of Batticaloa district in the Eastern Province of Sri Lanka in order to facilitate the dairy productivity.

The subsequent sections of this paper are as follows. The section immediately following this will describe theoretical and empirical studies on productivity analysis and on the dairy sector of Sri Lanka. It is followed by the section on research methods. Results and discussion is included in the penultimate section that will present conclusions and policy implications.

\section{Literature Review}

Characteristics of an extensive cattle rearing system, as described by Abeygunawardena et al., (1994) are; a) animals are allowed to feed on common grazing lands during the day; b) herd is kept in a paddock during the night; and c) the paddock is generally established near farmer's dwelling. Extensive rearing systems are considered as low-external input systems as; minimum use of commercial feeds; and lower investment in housing. As animals graze in scattered locations during the day approaching to animals during the day time is difficult. Usual grazing grounds include communal lands as tank catchment areas, tank beds, and jungles, and private paddy field after harvesting.

Bandara et al., (2011) studied dairying in upcountry farming systems based on vegetables and showed that about 25 per cent of farmers depended on zero-grazing. This is a marked difference between the DTVS as in the latter animals are allowed to graze during most of the time. Edirisinghe et al., (2006) using data from sample of 275 observations estimated technical efficiencies of dairy farming systems across the country. In the study, Eastern province dummy was found to be negative and significant when compared to the reference category of farms in Western Province. Central and North-central provinces had intercepts with lower values than the Eastern province. Although this can be interpreted correctly for the North-central province in which many systems follow extensive practices, the lower intercept for central province needs further attention as that province is one of the high production areas.

From consumption side, Bogahawatte and Herath (2006) recommended measures to increase domestic production of milk and subsequent improvements in distribution channels in the country to tackle the expected rise of demand for imported milk powder.

Consumers of yoghurt and curd in Anuradhapura, one of the major milk production districts in Sri Lanka indicated the preference for national brands over local brands for yoghurt (Divuldeniya \& Weligamage, 2016); while the preference of same households for curd made by national brands was less notable. 


\section{Theoretical Framework}

Two widely used methods in technical efficiency analysis are Stochastic Production Frontier (SPF) and Data Envelopment Analysis (DEA). These procedures follow parametric specifications. SPF method is based on an econometric specification of a generalized production function. Crosssectional data are used to estimate this function using a functional form researchers' choice. Stochastic Production Frontier (SPF) procedure was first developed by Aigner et al., (1977). It was then widely used by researchers in many sectors including rice and dairy. Paul and Shankar (2017) proposed an alternative specification for Technical efficiency analysis.

Dairy farms produce multiple outputs and outputs are considered joint products. These outputs include milk; manure; animals for slaughter; calves; and draft power. However, milk is the major output for which farmers plan to establish a herd. Consequently, we estimate a single-output production function for milk:

$$
y i=f(\mathbf{x} i j ; \boldsymbol{\beta}): \exp (\varepsilon i)
$$

Where $y_{\mathrm{i}}$ is the annual milk output per $\mathrm{i}^{\text {th }}$ herd, $x$ is the vector of input allocations to the herd. The subscripts $i$ and $j$ denote the herd/farm and inputs, respectively. The error term in this formulation is specific to the farm/herd. This can be separated into two independent components, as,

$$
\varepsilon_{\mathrm{i}}=\mathrm{v}_{\mathrm{i}}-\mathrm{u}_{\mathrm{i}} .
$$

The first element, $\mathrm{v}_{\mathrm{i}}$, is a random variable reflecting noise and other stochastic shocks entering into the definition of the frontier. These shocks include weather, luck, trade dispute occurrences, and similar events. This term is assumed to be an independent and identically distributed normal random variable (iid), with 0 mean, and constant variance.

The second component, $\mathrm{u}_{\mathrm{i}}$, captures technical inefficiency (TI) relative to the stochastic frontier.

Following Kumbhakar and Lovell (2000), the inefficiency term $u_{i}$ is assumed to be nonnegative and it is assumed to follow a half-normal distribution.

and

$$
\mathrm{TE}_{\mathrm{i}}=\mathrm{y}_{\mathrm{i}} /\left(\mathrm{y}_{\mathrm{i}}\right)^{*},
$$

$$
\mathrm{TI}=1-\mathrm{TE}_{\mathrm{i}}
$$




\section{Empirical Model Specification}

Milk production for the $i^{\text {th }}$ producer can be expressed using the stochastic Cobb-Douglas production function as a linear function in logarithms of output and input quantities. Considering all inputs to be potentially variable except land, we specify the annual production function for each herd (farm) as follows:

$\log y_{i}=\log \alpha+\sum_{j=1}^{m} \beta_{j} \log x_{i j}+\sum_{k=1}^{2} \beta_{k} D_{k j}+\sum_{j=1}^{m} \sum_{k=1}^{2} \beta_{j k} D_{k j} \log x_{i j}+e_{j}$

The Cobb-Douglas is the most widely used functional form in agricultural production. It has been used by researchers in explaining production technology at farm level (Weligamage, 2009) and in international productivity comparisons (Barker et al., 1985). Cobb-Douglas continued to be the choice of researchers estimating efficiency of dairy sector, Tauer and Belbase (1987); Cabrera, Solís, and Corral (2010). Our production function included inputs described in Table 1.

In the second stage analysis, technical efficiency score estimates (TE) for $\mathrm{i}^{\text {th }}$ herd/farm obtained from step one described above were regressed against selected farm and producer characteristics. Inefficiency model is given in the following equation,

$$
\mathrm{U}_{\mathrm{i}}=\mathrm{Z}_{\mathrm{i}} \delta+\mathrm{W}_{\mathrm{i}}
$$

Where,

$\mathrm{U}_{\mathrm{i}}=$ Efficiency component of technical inefficiency

$\mathrm{Z}_{\mathrm{i}}=$ Vector of explanatory variables associated with the technical inefficiency effects

$\delta=$ Vector of unknown parameter to be estimated

$\mathrm{W}_{\mathrm{i}}=$ Unobservable random variables

Explanatory variables used in this model are presented in Table 1.

Table 1: Description of variables used in analysis

\begin{tabular}{|c|c|c|}
\hline Variable & Description & Measurement \\
\hline \multicolumn{3}{|c|}{ Cobb-Douglas frontier production function } \\
\hline NBLC & adult local cattle & Count \\
\hline NBXE & cross/exotic cattle breeds & Count \\
\hline VETC & Veterinary cost & LKR \\
\hline NBMK & milking animals at present & Count \\
\hline FEDC & Cost of feed/concentrates & LKR \\
\hline
\end{tabular}


Table 1 contd...: Description of variables used in analysis

\begin{tabular}{lll}
\hline Variable & Description & Measurement \\
\hline Inefficiency & model & \\
HHAG & Age & Years \\
HHED & Education level & Years \\
HHGD & Gender of farmer (Dummy) & Male $=1 ; 0$ otherwise \\
FOMB & $\begin{array}{l}\text { farmer organization membership } \\
\text { (Dummy) }\end{array}$ & $\begin{array}{l}\text { Member }=1 ; 0 \\
\text { otherwise }\end{array}$ \\
HRDZ & $\begin{array}{l}\text { Herd size } \\
\text { usage of artificial insemination } \\
\text { ARTI }\end{array}$ & Number \\
& (Dummy) & Use=1;0 otherwise \\
\hline
\end{tabular}

\section{Data}

Respondents were selected from three Grama Niladhari (GN) divisions in Manmunai South West Division. Selected 52 dairy farming households were visited from November to December in 2016. Data on herd size, herd composition; grazing and other feeding practices; output and input quantities were collected using a pre-tested survey schedule. Data were analyzed using STATA.

\section{Results and Discussion}

Descriptive Statistics of the variables used are presented in Table 2.

Table 2: Descriptive statistics of variables used in analysis

\begin{tabular}{llrr}
\hline \multicolumn{1}{c}{ Variable } & \multicolumn{1}{c}{ Unit } & Mean & \multicolumn{1}{c}{ SD } \\
\hline Cobb-Douglas frontier production function & & \\
Milk output & 1 & 1255.8 & 786.2 \\
Adult local cows & Number & 6.3 & 4.0 \\
Cross/exotic cows & Number & 0.4 & 0.8 \\
Veterinary cost & LKR & 10861 & 7790.99 \\
Number of milking animals & Number & 2.7 & 1.9 \\
feed cost & LKR & 1366.10 & 1312.42 \\
& & & \\
Inefficiency model & & & \\
Age of household head & Years & 41.4 & 10.7 \\
Years of Education & Years & 5.6 & 4.0 \\
Herd size & Number & 6.7 & 4.4 \\
Gender Dummy & $1=$ male & 0.49 & 0.50 \\
FO member Dummy & $1=$ member & 0.68 & 0.48 \\
Usage of AI & $1=$ yes & 0.39 & 0.50 \\
\hline
\end{tabular}

Source: Household Survey, 2016 ( $\mathrm{n}=52)$

Note: Monetary values are in current LKR 
It can be learned from Table 2 that local cows dominate the herd as cross/improved breeds only account for 17 per cent of all adult cows in the sample. It also observed that 45 farms do not own at least one head of cross/improved cattle. Farmers revealed that costs for artificial insemination account for about 75 per cent of all veterinary costs. Success rate of the artificial insemination is was recorded as less than 30 per cent indicating that only around one-third of costs incurred for this practice is effective. Inability to identify heating incidences at corrects time; difficulty to reach cattle during the day time under the extensive rearing system; and is considered by farmers as the reasons for less success rate. Cost of feed/concentrates is 1,366.10 LKR per year. This is lower than the cost of feed in their rearing systems. Feed cost mainly account for poonac used to feed newly born calves. The average number of milking cows of a farm during the study time was recorded around two heads of cattle.

The average age of the household head/dairy farmer of the sample was observed as 41 years of old. Although, the old farmer has lots of experience, young farmer who has less experience may be more efficient than old farmer in cattle rearing. Hence, the age of the dairy farmer has both negative and positive effects for the technical efficiency of the farm and therefore, the expected sign was kept as ambiguous. The average number of years of schooling was recorded as 5.6 years. It says that each farmer has acquired at least 5.6 years of formal education. The expected sign of that was positive. Herd size was also mentioned as an influencing factor of the technical efficiency. The literature says that the male farmers can influence the technical efficiency of dairy productivity than female farmer. Therefore, being a male farmer was considered as having a positive effect on technical efficiency in the study. Like that, being a member of farmer organization and the usage of artificial inseminations for breeding were also considered as positive variables.

Table 3: Maximum likelihood estimation of the Cobb-Douglas stochastic production frontier

\begin{tabular}{|c|c|c|c|c|}
\hline Variable & Unit & Coefficient & SD & P-value \\
\hline Constant & & 6.3772 & 0.4776 & 0.0000 \\
\hline $\begin{array}{l}\text { Number of adult local } \\
\text { cattle }\end{array}$ & Number & -0.1338 & 0.0880 & 0.1280 \\
\hline $\begin{array}{l}\text { Number of cross/exotic } \\
\text { cattle breeds }\end{array}$ & Number & $0.0130 * * *$ & 0.0039 & $0.0001 * * *$ \\
\hline Veterinary cost per year & LKR & 0.0672 & 0.0532 & 0.2070 \\
\hline $\begin{array}{l}\text { Number of milking } \\
\text { animals at present }\end{array}$ & Number & $0.6677 * * *$ & 0.0490 & $0.000 * * *$ \\
\hline $\begin{array}{l}\text { Cost of feed/concentrates } \\
\text { per year }\end{array}$ & LKR & -0.0005 & 0.0489 & 0.9920 \\
\hline$\sigma_{\mathrm{v}}$ & & 0.1436 & & \\
\hline
\end{tabular}

$(\mathrm{n}=52), * * *=1 \%$, Model Statistics: $\mathrm{R} 2=0.750, \mathrm{~F}=4.797$

Source: Household Questionnaire Survey Data, 2016 
According to the results of the Cobb-Douglas model, the increasing number of animals of cross breeds and the number of available milking cows in a herd increases production. These parameters are significant at $1 \%$ level. This implies that increase in the number of cross/improved breeds as well as the number of available milking cows in a herd, will directly lead to increase the milk productivity in a herd. Distribution of farms by technical efficiency category is presented in Table 4. Determinants of Technical efficiency are presented in Table 5 .

Table 4: Distribution of technical efficiency scores of the sampled dairy farms

\begin{tabular}{ccc}
\hline Efficiency score range $(\%)$ & Frequency & $(\%)$ of Farms \\
\hline$<20$ & 3 & 5.8 \\
$21-40$ & 20 & 38.4 \\
$41-60$ & 22 & 42.3 \\
$61-80$ & 2 & 3.9 \\
$81-100$ & 5 & 9.6 \\
Mean & 49.6 & \\
Minimum & 12.0 & \\
Maximum & 94.6 &
\end{tabular}

Source: Household Questionnaire Survey Data, 2016 (n=52)

According to the Table 4, the mean technical efficiency score of the sample is recorded as 49.6 per cent. Efficiency scores in the sample vary between a minimum of 12 per cent to a maximum of 94.6 per cent. These results reveal that approximately 44.2 per cent of dairy farms are operated in categories below the average technical efficiency of the sample while the 13.6 per cent of farms are operated above the average efficiency level. Approximately, 42.3 per cent of farms are operated within the average range of the technical efficiency of the sample. Obtained average technical efficiency score is revealed that there is a potential to improve the technical efficiency of milk productivity by 50.4 per cent in the study area.

Table 5: Determinants of technical efficiency

\begin{tabular}{lccc}
\hline \multicolumn{1}{c}{ Variable } & Coefficient & SD & P-value \\
\hline Constant & -3.8808 & 0.2880 & 0 \\
HHAG & $-0.1160^{* *}$ & 0.0523 & 0.027 \\
HHED & $-0.2035^{*}$ & 0.1226 & $0.097^{*}$ \\
HHGD & $-0.4856^{*}$ & 0.2147 & 0.024 \\
FOMB & -0.9161 & 0.7209 & 0.204 \\
HRDZ & 1.1895 & 0.8817 & 0.177 \\
ARTI & 0.2859 & 0.7000 & 0.683 \\
\hline
\end{tabular}

Model Statistics: R2 $=0.526, \mathrm{~F}=9.635^{* * *}$

Source: Household Questionnaire Survey Data, $2016(\mathrm{n}=52), * *=5 \%, *=10 \%$ 
According to the technical inefficiency model, age of the dairy farmer is significant at 5 per cent significance level. Education level of the dairy farmer is significant at 10 per cent significant level of the dummy variable for gender. All these three variables have shown a negative relationship with the technical inefficiency. That implies the increasing of the number of years of experience (age) of the dairy farmer, increasing the number of formal years of schooling (education level) of the dairy farmer and the increasing of the number of cattle (herd size) in a herd will lead to increase the dairy productivity in a herd.

\section{Summary and Conclusions}

This study was carried out to analyze the technical efficiency and its determinants of cow milk production under the extensive cattle rearing system in Manmunai South West Divisional Secretariat in Batticaloa District. The analysis has revealed that the overall milk producers have achieved an average technical efficiency of 49.6 per cent. It indicates that there is about $50.4 \%$ potential to improve their technical efficiency of milk production. Number of cross/improved breeds in a herd and the number of available milking cows were significant in the production frontier analysis. Age of the farmer, herd size and the education level of the farmer were significant in the inefficiency model. As an overall, the study explains the importance of the investing on cross/improved breeds as well as on the available milking cows to increase the technical efficiency of a farm unit under the extensive rearing system in the study area. Further, it recommends facilitating dairy farmers to acquire more experience, technical knowledge and proper herd management practices to support dairy productivity improvements in their herds.

\section{References}

Abeygunawardena H, D. Rathnayaka and M.W.A.P. Jayatilake (1994). Characteristics of Cattle Farming Systems in Sri Lanka, Journal of National Science Council Sri Lanka, 25(1), 25-38.

Aigner, D., K. Lovell and P. Schmidt (1977). Formulation and Estimation of Stochastic Frontier Production Function Models. Journal of Economeetrics, 6, 21-37.

Barker, R., R.W. Herdt and Beth Rose (1985). The Rice Economy of Asia. Resources for the Future: Washington, DC.

Bandara, D.M.D.S., S. Premaratne and C.M.B. Dematawewa (2011). Production and Economic Characteristics of Intensive and SemiIntensive Dairy Cattle Management Systems in Vegetable Based Farming System in Welimada. Tropical Agricultural Research, 22(3), 314-323. 
Bogahawatte, C. and J. Herath (2010). Factors affecting Import Shares of Powdered Milk and other Milk Products and their Implications in Sri Lanka. Sri Lankan Journal of Agricultural Economics, 8, 21-30. http://doi.org/10.4038/sjae.v8i0.1827

Cabrera VE1, D. Solís and J. del Corral (2010). Determinants of Technical efficiency among Dairy Farms in Wisconsin. Journal of Dairy Science, 93(1), 387-93. doi: 10.3168/jds.2009-2307.

Cuesta, R.A. (2000). A Production Model with Firm-Specific Temporal Variation in Technical Inefficiency: With Application to Spanish Dairy Farms. Journal of Productivity Analysis, 13, 139-158.

Diwuldeniya, D.W.K.S. and P. Weligamage (2015). Consumption Patterns and Preferences of Households for National and Local Brands of Yoghurt and Curd: A Study in Anuradhapura District. Inclusive Growth towards Economic Transformation Sri Lanka Economics Research Conference. 82-86.

Edirisinghe, J., M. Edirisinghe and D. Auwardt (2010). Reasons for Variations in the Levels of Efficiency in Smallholder Dairy Milk Production in Sri Lanka: A Cross Sectional Data Analysis. Journal of Food and Agriculture, 1(2), 30-39. http://doi.org/10.4038/jfa.v1i2.1797

Gunarathne, A., H. Kono, S. Kubota and K. Karunagoda (2015). The Impact of Socio-economic Factors on Milk Production Cost and Marketing Channel - A Case Study of Marginal Farms in Kurunegala District of Sri Lanka. Japanese Journal of Farm Management, 52(3).

Kumbhakar, S. and K. Lovell (2000). Stochastic Frontier Analysis. Cambridge Univ. Press, Cambridge, UK.

Paul, S. and S. Shankar, S. (2017). An Alternative Specification for Technical Efficiency Effects in a Stochastic Frontier Production Function, Crawford School working paper 1703, Crawford School of Public Policy, The Australian National University.

Serasinghe, R.N., M.B.P. Mahipala and L.H.P. Gunaratne (2003). Comparison of Stochastic Frontier Analysis (SFA) and Data Envelopment Analysis (DEA). Tropical Agricultural Research, IS, 217-225.

Tauer, L. and K. Belbase (1987). Technical Efficiency of New York Dairy Farms. Northeastern Journal of Agricultural and Resource Economics, 16(1), 10-16. http://doi:10.1017/S0899367X00000313 